\title{
Evolution and Future Generation of TV
}

\author{
Sandeep Joshi \\ Department of Electronics \& Communication Engineering, Shiv Nadar University, Uttar Pradesh, India \\ Email: sandeepjoshi@ieee.org
}

S.L. Maskara

Soura Niloy housing complex, 1, Kailash Ghosh road Block-G, Flat-2W, Kolkata, Pin 700008, India

Email: maskara.shankar@gmail.com

\begin{abstract}
No other electronic media has created as much mass impact as the TV. TV is both a personal as well as family/community device which makes it reach a large population. Obviously the immense popularity of TV has resulted in an unprecedented growth of TV viewing as well as technology. From the simple TV today one can have a smart TV with varying features satisfying all sections of society. The TV technology has grown in all aspects namely the TV studio technology, the TV transmitter \& broadcast technology and the TV receiving device technology. Not only have the TV signals been converted from analog to digital, today one has high definition TV, the IPTV, the mobile TV and the 3D TV commercially available. It is very interesting and important to trace the evolution of TV technology from its basic form as in 1930s to date and to visualize their technical features at various stages of developments. This paper gives an overview of the developments in TV technology highlighting their important features.
\end{abstract}

Index Terms_IPTV; MPEG; Compression; Mobile TV; Digital TV

\section{INTRODUCTION}

TV has become a very popular and common household item world over. Its capability of providing entertainment, news, various other useful information such as weather, political, scientific, agricultural, disasters, current developments, etc., video gaming, lessons in education, health care guidance \& travel and tourism details to people sitting at their home at reasonably affordable cost have made it very popular. All these capabilities are the result of research and the advances in technology in many fields. In a relatively short period of less than three quarters of a century, the TV can be regarded as one of the marvelous inventions. Combined with the computer, internet and web technologies, TV today is becoming an excellent example of convergence of communication, computers and broadcasting. It offers today web browsing, interactive communication and social networking. Technically the information content of video signals is very high (thousand times the voice information) and as such its transmission and broadcasting by conventional means would require a very high bandwidth which would be practically impossible. The advances in coding, compression and signal processing techniques have made the low bandwidth video possible. This has further resulted in making a large number of TV channels and programs available in a limited RF spectrum.

In this paper the evolution of TV has been presented with important features. The next section describes the evolution of analog, digital and the HDTV. The third section contains the features of future generation TV such as IPTV, 3DTV, Mobile TV and smart TV. The last section gives a brief conclusion on progress of TV.

\section{EVOLUTION OF TV}

\section{A. Analog TV}

Television implies viewing motion far from the observer that is to see at a distance. It is a method of transmitting and receiving a scene which is in motion as seen by human eye and heard by human ear, with the help of radio broadcasting or transmission cable. Motion picture reproduces still picture in the form of a snapshot. If these snapshots are shown one after the other in a fast sequence they give an illusion to human eye that it is a moving picture. Therefore television should be able to transmit and receive a still picture. For transmission and reception of visual information that is picture the system should have a camera tube and an image reproducing tube called as TV system. The famous camera tubes used are Orthicon Tube - based on photoelectron emission and Vidicon tube- based on photo conductivity [1], [2]. Each image is divided into small elements called image element, picture element, pel or pixel. To view the image it has to be read point by point which is called as Scanning. It is the process required for transmission of picture which is divided into horizontal lines called raster, element by element. It is done by an electron beam, which scans horizontally as well as vertically. Interlaced horizontal scanning divides total number of lines in the frame into two parts. In countries where the frequency of transmission is $60 \mathrm{~Hz}$ frame rate is 30 frames per second 
and where the frequency is $50 \mathrm{~Hz}$ then the frame rate is 25 frames per second. TV resolution can be described [3] measured and specified in different ways

- Number of lines per (mm or inch) both horizontally and vertically.
- $\quad$ Number of line pairs per (mm or inch) vertically and horizontally.

- Number of lines per total display- Lines per picture height (LPH)

TABLE I.

SUMMARY OF ANALOG TV STANDARDS

\begin{tabular}{|c|c|c|c|c|c|}
\hline Standard & $\begin{array}{c}\text { Number of } \\
\text { lines }\end{array}$ & $\begin{array}{c}\text { Video } \\
\text { B.W.(MHz) }\end{array}$ & Frequency bands (MHz) & $\begin{array}{c}\text { Channel B. } \boldsymbol{W} \\
\text { (MHz) }\end{array}$ & $\begin{array}{c}\text { Sound } \\
\text { modulation }\end{array}$ \\
\hline CCIR B,G & 625 & 5 & $47-68,174-230 \& 470-853$ & 7 or 8 & FM \\
\hline OIRT D & 625 & 6 & $48.5-100,174-230$ & 8 & FM \\
\hline French VHF E & 819 & 10.6 & $50-70,160-215$ & 13.15 & AM \\
\hline FCC USA M & 525 & 4.2 & $54-88,174-266,470-890$ & 6 & FM \\
\hline
\end{tabular}

Color helps human eye to perceive the information better and extract the information from the scene, this motivation led to color TV design. To compress a color image the transformation to the RGB representation of image is a more effective compression method. Primary colors are red, blue and green, they are sent in independent combination denoted as $E_{Y}$ Luminance signal and $\mathrm{E}_{\mathrm{I}}, \mathrm{E}_{\mathrm{Q}}$ called chrominance signals or color difference signals. For TV transmission Vestigial Side Band (VSB) modulation is used. TV stations are assigned channels in VHF and UHF bands. Table I gives an overview of Analog TV standards [4].

\section{B. Digital TV}

Digital technology has an edge over analog in combating noise so to increase the clarity of signal there has been a shift towards digital techniques. Digitization leads to many advantages like easy detection at the receiver, reduction in power required for the transmission, cost of digital transmission is less, biggest advantage being improvement in SNR even without use of error control coding techniques compared to analog transmission, but at the same time demands higher bandwidth for operation. With the development in compression techniques and bandwidth efficient modulation techniques digital transmission has become a reality. Digital TV [5], [6] has removed the line of distinction between the computer and TV and merged TV and computing because of the digital representation of image and video. Fig.1 gives the basic block diagram of DBS-TV transmission.

Digital TV also called as Direct Broadcast Satellite (DBS) TV and Direct to Home (DTH) TV. It is broadcasted using satellite system, where before transmission the signals which may originate from various sources are converted to digital, compressed, time division multiplexed and QPSK modulated before transmitting on uplink to the satellite transponder. The receiver unit at home of the user has an important device called Digital Set top box which provides the user the access to various digital content. The basic work of these set top boxes is translation of signals in the format that can be displayed on the screen. The set top box should have capability to support cable, terrestrial, satellite, IP broadcasting, as well have hybrid capability. They should stream data from anywhere in the world whether it is occurring live or stored in some device and should provide high quality user experience.

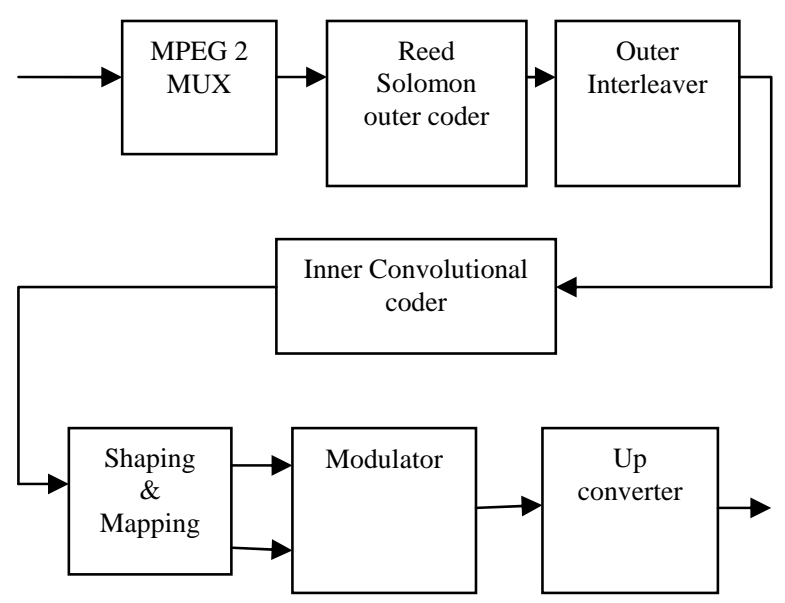

Figure 1. DBS TV Transmission Block Diagram

The set top box contains various parts, some of the important components are

- Digital information Processor

- Microcontroller

- Video interface unit

- Audio Interface unit

- User interface unit 
- Connectivity

- $\quad$ Power converter

Fig.2 gives a broad overview of digital television broadcasting system at production, transmission and receiving ends [4].

As the bandwidth required for digital transmission is very high compared to that required for analog transmission so there is a strong need for compression of coded video bits before transmission. The predictive coding does the compression of each pixel by quantizing the difference between the actual and the predicted value based on the coding techniques employed, whereas the transform coding employs Discrete Cosine Transform (DCT).

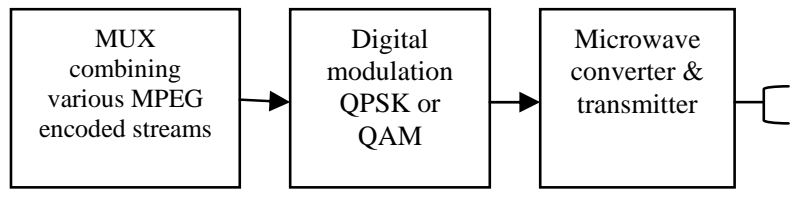

TV production station

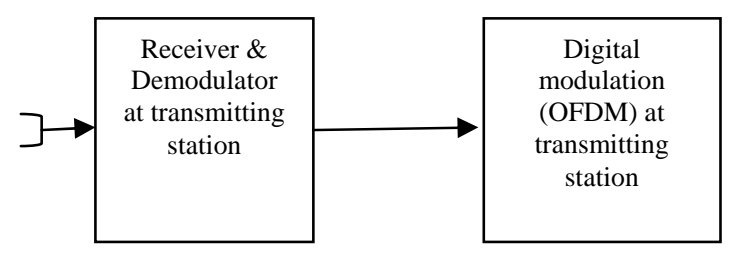

Digital TV transmitter station

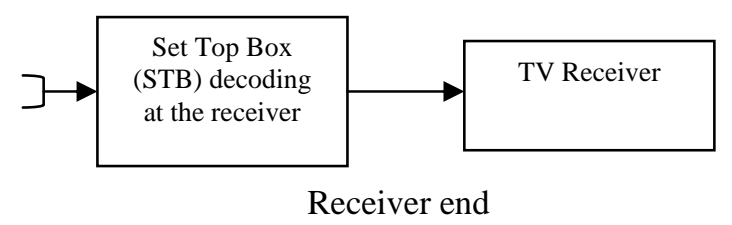

Figure 2. Digital TV Broadcasting System

Advantage of DCT is that using it the samples are de correlated so that they can be compressed independent of each other. For standardization of video coding for digital TV efforts were done by ISO's MPEG (Moving Pictures Expert Group). Before MPEG, CCITT recommendation H.261 defined a video codec. MPEG [7] has now collaborated with various world representatives to evolve a unified standard. In developing these standards an important factor which is taken into account is human visual system. With the improvement in motion picture compensation techniques coding efficiency has improved widely. The H.264/AVC [8] standard offers advantages in terms of improvement of coding efficiency, error robustness enhancement and flexibility that can be used over a variety of applications. Video coding layer (VCL) design of $\mathrm{H} .264$ is based on block based motion compensated hybrid video coding concepts but when compared to previous standards some notable differences include
- Improvement in motion prediction

- Small block size is used.

- Improvement in de blocking filters

- Coding method is enhanced.

Another important aspect of digital transmission is bandwidth efficient modulation techniques employed for transmission. With the entertainment becoming on the go we as a user want to control what to watch, when to watch and want more and more services, the modulation techniques employed play a vital role in providing all the services. Table II gives a comparison of basic compression and modulation techniques used for audio and video information [9].

\section{HDTV}

High Definition TV is essentially digital TV which differs in many ways compared to conventional TV; the screen used in HDTV [10] is wider with an aspect ratio of 16:9, high resolution, and improved picture quality with no artifacts, ghosts and snow, with digital sound and high resolution.

TABLE II. SUMMARY OF AUDIO \& VIDEO CODING \& COMPRESSION TECHNIQUES FOR TV

\begin{tabular}{|c|c|c|c|c|}
\hline $\begin{array}{l}\text { Data } \\
\text { type }\end{array}$ & Data format & $\begin{array}{c}\text { Coding } \\
\text { \& } \\
\text { Compre } \\
\text { ssion } \\
\text { Techniq } \\
\text { ue }\end{array}$ & $\begin{array}{l}\text { Compressed } \\
\text { data rate }\end{array}$ & $\begin{array}{c}\text { Uncompr } \\
\text { essed } \\
\text { data rate }\end{array}$ \\
\hline Voice & $\begin{array}{c}4 \mathrm{kHz} \text { speech } \\
\text { signal }\end{array}$ & $\begin{array}{l}\text { ADPC } \\
\text { M }\end{array}$ & 32 kbps & 64kbps \\
\hline Voice & $\begin{array}{c}4 \mathrm{kHz} \text { speech } \\
\text { signal }\end{array}$ & RELP & 16 kbps & 64kbps \\
\hline Voice & $\begin{array}{c}4 \mathrm{kHz} \text { speech } \\
\text { signal }\end{array}$ & CELP & $8 \mathrm{kbps}$ & 64 kbps \\
\hline Music & $\begin{array}{c}16-24 \mathrm{KHz} \\
\text { audio }\end{array}$ & MP3 & $\begin{array}{c}32-384 \\
\text { Kbps }\end{array}$ & $\begin{array}{c}512-748 \\
\text { Kbps }\end{array}$ \\
\hline Image & $\begin{array}{c}8 \times 10 \text { inch } \\
\text { photo scanned } \\
\text { at } 400 \text { pixels } \\
\text { per inch }\end{array}$ & JPEG & $\begin{array}{l}1.2-8 \\
\text { Mbytes }\end{array}$ & $\begin{array}{c}38.4 \\
\text { Mbytes }\end{array}$ \\
\hline Video & $\begin{array}{l}176 \times 144 \\
\text { frames at } 10 \\
\text { frames per } \\
\text { second }\end{array}$ & Н.261 & $\begin{array}{c}\text { 64kbps- } \\
1.544 \text { Mbps }\end{array}$ & $\begin{array}{l}2-36.5 \\
\text { Mbps }\end{array}$ \\
\hline Video & $\begin{array}{l}\text { 1920x1080 } \\
\text { frames at } 30 \\
\text { frames per } \\
\text { second }\end{array}$ & $\begin{array}{l}\text { MPEG- } \\
2\end{array}$ & 19-38 Mbps & $1.6 \mathrm{Gbps}$ \\
\hline
\end{tabular}


TABLE III.

COMPARISON OF ANALOG AND DIGITAL TV STANDARDS

\begin{tabular}{|c|c|c|c|c|c|}
\hline $\begin{array}{c}\text { TV } \\
\text { standar } \\
\text { ds }\end{array}$ & $\begin{array}{l}\text { Total } \\
\text { lines }\end{array}$ & $\begin{array}{l}\text { Resoluti } \\
\text { on }\end{array}$ & $\begin{array}{l}\text { Compres } \\
\text { sion } \\
\text { format }\end{array}$ & $\begin{array}{c}\text { B. W } \\
\dot{(M} \\
\dot{H z})\end{array}$ & $\begin{array}{c}\text { Aspe } \\
\text { ct } \\
\text { ratio }\end{array}$ \\
\hline PAL & 625 & $720 \times 575$ & Analog & 8 & $4: 3$ \\
\hline $\begin{array}{l}\text { SECA } \\
\mathrm{M}\end{array}$ & 625 & $720 \times 575$ & Analog & 8 & $4: 3$ \\
\hline NTSC & 525 & $720 \times 486$ & Analog & 6 & $4: 3$ \\
\hline DVB & 1250 & $\begin{array}{c}1920 \times 11 \\
52\end{array}$ & MPEG-2 & $7-8$ & $16: 9$ \\
\hline HDTV & 1125 & $\begin{array}{c}1920 \times 10 \\
80\end{array}$ & MPEG-2 & 6 & $16: 9$ \\
\hline
\end{tabular}

An HDTV picture when compared to conventional television picture carries around six times more information. HDTV also provides viewers the benefit of Picture-in-picture (PIP) and Picture-outside-picture (POP). Table III gives a comparison of analog and digital TV standards.

An important reason for increase in the popularity of HDTV is availability of PC displays with high definition and their affordability, also the industry is widely supporting HDTV for example Microsoft Vista allows users to put their digital cable into their digital PC to view HDTV. Further the development of new standards like MPEG4 (H.264) and Windows media 9 which have achieved twice the compression efficiency as compared to MPEG2 have made HDTV which uses large number of pixels and high bandwidth a reality. Table IV gives an overview of the video bandwidth requirements for different TV standards. HDTV has made viewer the part of broadcast that while viewing feels that he is part of the scene. The growth of HDTV is an important milestone in the broadcasting and is inspired by wide screen movies.

TABLE IV.

VIDEO TV BANDWIDTHS OF DIFFERENT STANDARDS

\begin{tabular}{|c|c|c|c|}
\hline $\begin{array}{c}\text { Standards/Form } \\
\text { ats }\end{array}$ & $\begin{array}{c}\text { Aspect } \\
\text { Ratio }\end{array}$ & Resolution & B.W. \\
\hline $\begin{array}{l}\text { Black and white } \\
\text { TV }\end{array}$ & $4: 3$ & $625 \times 800$ & $\begin{array}{c}6.5 \\
\mathrm{MHz}\end{array}$ \\
\hline SDTV & $4: 3$ & $720 \times 480$ & $\begin{array}{l}5.18 \\
\mathrm{MHz}\end{array}$ \\
\hline \multirow{2}{*}{ HDTV } & \multirow[t]{2}{*}{$16: 9$} & $1280 \times 720$ & $\begin{array}{l}13.8 \\
\mathrm{MHz}\end{array}$ \\
\hline & & $1920 \times 1080$ & $\begin{array}{l}31.1 \\
\mathrm{MHz} \\
\end{array}$ \\
\hline Mobile TV & $4: 3$ & $350 \times 240$ & $\begin{array}{l}2.52 \\
\mathrm{MHz}\end{array}$ \\
\hline
\end{tabular}

\section{FUTURE GENERATION TV}

The TV called as idiot box has now become smart and is integrated with the internet and computer networks changing the future of home entertainment. The present Entertainment network will transform into converged network which will be packet based in future. Each host in the internet is defined by a unique address called IP address which is globally unique.

\section{A. IPTV}

IPTV or Internet Protocol Television is a scheme that uses IP networking protocol to transport data. Some of the features of IPTV are

- $\quad$ Support for interactive TV like Live TV

- User interaction based gaming services

- High speed internet browsing.

- Personalization of TV services

- Low bandwidth requirements

- $\quad$ IPTV can be viewed on many devices other than TV like PC and mobile devices.

IPTV differs from terrestrial broadcasting TV [7] as IPTV is interactive that is two way user sends his requests and based on that receives the services where as terrestrial broadcasting TV is one way. Management in Terrestrial broadcasting TV is almost nil whereas IPTV is fully managed including the billing, also the streaming in terrestrial TV systems is simultaneous whereas in IPTV systems it is in bundles. With the IP wave and with every network being IP based it is a natural further step to go to the IPTV. According to ITU focus group (ITU-T FG IPTV) IPTV is defined as "Multimedia services such as $\mathrm{TV}$, video, audio, text, graphics and data delivered over IP based networks managed to provide required level of Quality of service and experience, security, interactivity and reliability". This scheme takes into advantages of packetization of data as is done in existing computer data networks. With packetizing of data we are able to utilize the network more efficiently and the need for dedicating a particular channel for transmission as was done in circuit switching is overcome.

IPTV is often confused with Internet TV but they differ in many ways. Table $\mathrm{V}$ gives difference between an Internet TV also known as Online TV and IPTV also known as Web TV. 
TABLE V.

INTERNET TV AND IPTV COMPARISON

\begin{tabular}{|c|c|c|}
\hline Parameters & Internet TV & IPTV \\
\hline Platforms & $\begin{array}{l}\text { Uses public } \\
\text { internet }\end{array}$ & $\begin{array}{l}\text { Uses dedicated } \\
\text { private networks }\end{array}$ \\
\hline $\begin{array}{l}\text { Quality } \\
\text { video }\end{array}$ & $\begin{array}{lr}\text { Not } & \text { guaranteed } \\
\text { since } & \text { operates } \\
\text { over } & \text { free } \\
\text { network } & \end{array}$ & $\begin{array}{c}\text { Guaranteed good } \\
\text { quality }\end{array}$ \\
\hline $\begin{array}{l}\text { Access } \\
\text { mechanism } \\
\text { used }\end{array}$ & PCs can be used & $\begin{array}{l}\text { Set top boxes are } \\
\text { required }\end{array}$ \\
\hline Security & $\begin{array}{l}\text { Unsecured as } \\
\text { users } \\
\text { authenticity not } \\
\text { known }\end{array}$ & $\begin{array}{l}\text { Fully secured, } \\
\text { users IP address } \\
\text { are used }\end{array}$ \\
\hline $\begin{array}{l}\text { Common } \\
\text { examples }\end{array}$ & $\begin{array}{l}\text { BBC's iPlayer } \\
\text { and Apple TV }\end{array}$ & $\begin{array}{c}\text { Microsoft's } \\
\text { XBOX } 360 \text { IPTV }\end{array}$ \\
\hline
\end{tabular}

IPTV aims at converging the existing Telecommunication and digital broadcast services. There are various options available to the service providers to provide IPTV, the present networking technologies like DSL, Wireless network, Satellite, Internet, Cable TV, etc, can be used to deliver IPTV. Each device is identified by the IP address in a network delivering IPTV. While deploying a service provider should opt for IPv6 since it uses 128 bit addressing scheme compared to 32 bits scheme used by IPv4 thus increasing number of addresses many times, also the backward compatibility of IPv6 addresses and greater security makes it preferred choice for network providers. At the user end an important device to support IPTV is IP digital Set top box which provides an important interface between the service provider and the user end device like flat screen display, supported by remote control helps user to navigate all features including Electronic Program Guide (EPG). Some of the IPTV applications include IPTV Internet browsing, E-mail, on demand Gaming, Interactive advertising on IPTV, and many more.

The two important QoS [11] factors in IPTV are

- Packet loss ratio (\%) : (Number of packets lost / Number of packets transmitted) x 100

- Data Throughput (bps) : (Number of packets received $x$ Number of bits per packet) / (Time in seconds )

\section{B. $3 D T V$}

The concept of 3D TV [12] was demonstrated after a few years of the invention of $2 \mathrm{D} \mathrm{TV}$, but was based on the concept of stereoscopy whereas the current research focus is on the advancement of the principle of stereoscopy like goggle free auto stereoscopic devices. The 3D TV is based on following two concepts

- Stereoscopy: this is based on human perception. Same scene is captured from two different angles and then sent to the left and right eyes. The two eyes receiving two different version of same scene send the information to brain which interprets the scene as 3D.

- Holography: it is based on recording and reconstructing of light along with its properties and is not based on human perception. The amplitude and phase distribution of light are recorded over a surface which when illuminated gives the same light.

To create the replica of a 3D scene following steps will be involved in 3D TV chain

- $\quad 3 D$ scene capture

- Representation

- Coding and Compression

- Transmission

- Signal Conversion

- Display

These steps are also important challenges [13] to be overcome in making 3D TV viewing a reality. Applications of $3 \mathrm{D}$ video technologies to will change the way we interact with visual data and finds applications in many fields like communications, entertainment, medicine, education, navigation to name a few.

\section{Mobile TV}

With the growth of Telecommunication worldwide and the advent of new technologies like 3G, WiMax and wireless broadband the desire of on the go communication has increased manifolds and so are the services being provided, Mobile TV [14] being one of them. The data streamed would be further compressed so that it can be viewed in the mobile device where screen size is small compared to desktop devices. Some commonly used formats are summarized in Table VI

Digital Multimedia uses various file formats but Mobile Multimedia involves use of formats those are standardized by 3GPP (Third Generation Partnership Project) and various industrial alliances which are involved in mobile industry. The two most used broadcast technologies available for Mobile TV both working in UHF are

- $\quad$ DVB-H : used in GSM with air interface being Coded OFDM

- $\quad$ MediaFLO $^{\mathrm{TM}}$ : used in CDMA with air interface being CDMA (Qualcomm).

Mobile TV would mean that there is at least one wireless link between the service provider and user and 
therefore the challenges faced would be same as those faced by wireless link. Compared to fixed terminal the problem in wireless are

- Mobile Receiver Equipment

- Bandwidth requirement

- Wireless channel

- Coverage area

These problems in wireless links are overcome with growth of technology. Mobile TV seems the technology for future providing users in true means on the go services which include entertainment services as well.

TABLE VI.

SOME COMMON DISPLAY FORMATS IN MOBILE TV

\begin{tabular}{|l|l|}
\hline \multicolumn{1}{|c|}{ Format } & \multicolumn{1}{c|}{ Pixels } \\
\hline $\begin{array}{l}\text { CIF (Common Intermediate } \\
\text { Format) }\end{array}$ & $352 \times 288$ pixels \\
\hline $\begin{array}{l}\text { SIF (Standard Interchange } \\
\text { Format) }\end{array}$ & $320 \times 240$ pixels \\
\hline QCIF (Quarter CIF) & $176 \times 144$ pixels \\
\hline
\end{tabular}

D. Smart TV

Notion of TV as idiot box is being challenged by the TV manufacturers by taking cue from the smart phones. Some of the features of smart TV include

- Feature search and access

- Built in web browser

- Downloadable games and applications

- Media sharing with devices on the same network

- $\quad$ Social networking such as Facebook, Twitter

- Interactive communication such as Skype with Video calling

- $\quad$ Photo sharing such as Flickr, Picasa

- Audio and Video streaming such as You tube

- Updated News, Information and Weather.

\section{CONCLUSIONS}

This short paper presents an overview of progress of TV from its beginning to date giving important technical features at various stages of development and deployment. It is known that the TV occupies a very important place in life of almost every person. Its popularity and importance makes one curious to know how this device was developed and has reached a high level of advancement. Through the technical features an attempt has been made to unfold the basic techniques behind this mysterious box. The important milestones of TV evolution are Analog, Digital, High density, Internet TV, 3D TV, Mobile TV and the Smart TV. The underlying techniques are camera tubes, scanning, modulation, digital coding, bandwidth compression, error control coding global broadcasting (through satellite), packetization, 3 dimensional representation \& transmission, integration with mobile phones, the display devices and the user friendly control as in the smart TV. All these techniques are really quite intricate in concept, theory and finally implementation. Many challenges have been faced and hurdles overcome in developing and advancing the TV. Finally it will not be inappropriate to say that TV has an interesting success story proving how the technology converts a dream and the scientific idea into reality.

\section{REFERENCES}

[1] Z.M. Prusluin and M.A. Smirnova, Radio Engineering and Electronics, MIR Publishers, Moscow, 1971

[2] F.E. Terman, Electronics and Radio engineering, $4^{\text {th }}$ ed, McGraw hill, 1955.

[3] www.hdtvinfoport.com

[4] Punchihewa, A., "Tutorial on digital terrestrial television broadcasting," Information and Automation for Sustainability (ICIAFs), 2010 5th International Conference on ,pp.58-63, 17-19 Dec.2010,doi:10.1109/ICIAFS.2010.5715635 http://ieeexplore.ieee.org/stamp/stamp.jsp?tp=\&arnu mber $=5715635$ \&isnumber $=5715624$

[5] Dimitris Anastassiou, “Digital Television”, Proceedings of IEEE, vol. 82, no.4, April 1994.

[6] Arun Netravali, and Andrew Lippman, "Digital Television:A Perspective”, Proceedings of IEEE, vol.83, no. 6, June 1995.

[7] Julien Maisonneuve, Muriel Deschanel, Juergen Heiles, Wei Li, Hong Liu, Randy Sharpe, and Yiyan Wu, "An overview of IPTV standards Development”, IEEE Transactions on broadcasting, vol. 55, no.2, June 2009

[8] Gary J. Sullivan, and Thomas Wiegand, "Video Compression-From Concepts to H.264/AVC standard”, Proceedings of IEEE, vol. 93, no. 1, January 2005.

[9] Alberto Leon-Garcia and Indra Widjaja, Communication Networks Fundamental concepts and key architectures, $2^{\text {nd }}$ ed, Tata McGraw Hill, 2003.

[10] Sadiku, M.N.O.; Nelatury, S.R. , "High definition television in detail," Potentials, IEEE , vol.26, no.1, pp.31-35,Jan.-Feb.2007, doi:10.1109/MP.2007.343038 http://ieeexplore.ieee.org/stamp/stamp.jsp?tp=\&arnu mber $=4147709$ \&isnumber $=4147540$

[11] Soohong Park; Seong-Ho Jeong, "Mobile IPTV: Approaches, Challenges, Standards, and QoS Support," Internet Computing, IEEE, vol.13, no.3, pp.23-31,May-June2009, doi:10.1109/MIC.2009.65 http://ieeexplore.ieee.org/stamp/stamp.jsp?tp=\&arnu mber $=4907683 \&$ isnumber $=4907674$ 
[12] www.3dtv-research.org

[13] Levent Onural, “Signal processing and 3DTV,” IEEE Signal processing magazine, Sep 2010

[14] Amitabh Kumar, Implementing Mobile TV, 2nd ed, 2010, Elsevier.

Sandeep Joshi is working as a faculty in Electronics and Communication Engineering Department at Shiv Nadar University, Uttar Pradesh, India. He received his M.E. degree in Communication Engineering from Birla Institute of Technology \& Science, Pilani, India. He is a member of IEEE, life member of ISTE (Indian Society for Technical Education) and Associate Member lifetime of IETE (Institution of Electronics and Telecommunication Engineers). His research interests include Wireless communication and Next generation networks.

S.L. Maskara is Life Senior Member of the IEEE, Life Fellow of the IETE, Life Fellow of the IE (India), Life Senior Member of the CSI, Life Member of the ISTE. He obtained Ph.D. in Electronics \& Electrical Comm. Engg. in 1977 from IIT Kharagpur; M.E. in Electrical Comm Engg in 1966 from IISc Bangalore; B.Sc. Engg in Telecom. Engg. in 1963 from BIT Sindri, Ranchi Univ. His research interests include Telecommunication Switching, Systems \& Networks; Wireless, Mobile, Satellite, Optical \& Computer Communications \& Networking; Spread Spectrum, Error Control Coding \& Multiple Access including CDMA Techniques; Engineering Education including Curriculum Planning and Design.

He has a long teaching \& research experience of 46 years. He worked as Dean Ac \& Res at JIIT Noida 2006-11; Dist Prof. at LNMIIT Jaipur 2005-06 \& also at DAIICT Gandhinagar 2004-05; Lect./Asst Prof./Prof. in the E\&ECE at IIT Kharagpur 1966-2004; faculty member in Telecom Engg. at BIT Sindri, 1963-64 